\title{
Double deficiency in IL-17 and IFN- $\gamma$ signalling significantly suppresses the development of diabetes in the NOD mouse
}

\author{
G. Kuriya • T. Uchida • S. Akazawa • M. Kobayashi • K. Nakamura • \\ T. Satoh • I. Horie • E. Kawasaki • H. Yamasaki • L. Yu • Y. Iwakura • \\ H. Sasaki • Y. Nagayama • A. Kawakami • N. Abiru
}

Received: 6 December 2012 / Accepted: 22 April 2013 / Published online: 23 May 2013

(C) Springer-Verlag Berlin Heidelberg 2013

\begin{abstract}
Aims/hypothesis $\mathrm{T}$ helper type (Th) 17 cells have been shown to play important roles in mouse models of several autoimmune diseases that have been classified as Th1 diseases. In the NOD mouse, the relevance of Th1 and Th17 is controversial, because single-cytokinedeficient NOD mice develop diabetes similarly to wildtype NOD mice.

Methods We studied the impact of IL-17/IFN- $\gamma$ receptor double deficiency in NOD mice on the development of insulitis/diabetes compared with IL-17 single-deficient mice and wild-type mice by monitoring diabetes-related phenotypes. The lymphocyte phenotypes were determined by flow cytometric analysis.

Results IL-17 single-deficient NOD mice showed delayed onset of diabetes and reduced severity of insulitis, but the cumulative incidence of longstanding diabetes in the IL-17deficient mice was similar to that in wild-type mice. The IL$17 / \mathrm{IFN}-\gamma$ receptor double-deficient NOD mice showed an
\end{abstract}

G. Kuriya and T. Uchida contributed equally to this study.

Electronic supplementary material The online version of this article (doi:10.1007/s00125-013-2935-8) contains peer-reviewed but unedited supplementary material, which is available to authorised users.

G. Kuriya $\cdot$ S. Akazawa $\cdot$ M. Kobayashi $\cdot$ K. Nakamura $\cdot$

T. Satoh $\cdot$ I. Horie $\cdot$ A. Kawakami $\cdot$ N. Abiru $(\bowtie)$

Department of Endocrinology and Metabolism,

Unit of Translational Medicine, Nagasaki University Graduate

School of Biomedical Sciences, 1-7-1 Sakamoto,

Nagasaki 852-8501, Japan

e-mail: abirun@nagasaki-u.ac.jp

T. Uchida $\cdot$ H. Sasaki

Department of Hospital Pharmacy, Nagasaki University Graduate

School of Biomedical Science, Nagasaki, Japan

E. Kawasaki

Department of Metabolism/Diabetes and Clinical Nutrition,

Nagasaki University Hospital, Nagasaki, Japan apparent decline in longstanding diabetes onset, but not in insulitis compared with that in the IL-17 single-deficient mice. We also found that double-deficient NOD mice had a severe lymphopenic phenotype and preferential increase in regulatory $\mathrm{T}$ cells among $\mathrm{CD}^{+} \mathrm{T}$ cells compared with the IL-17 single-deficient mice and wildtype NOD mice. An adoptive transfer study with $\mathrm{CD} 4{ }^{+} \mathrm{CD} 25^{-} \mathrm{T}$ cells from young non-diabetic IL-17 single-deficient NOD mice, but not those from older mice, showed significantly delayed disease onset in immune-deficient hosts compared with the corresponding wild-type mice.

Conclusions/interpretation These results indicate that IL17/Th17 participates in the development of insulitis and that both IL-17 and IFN- $\gamma$ signalling may synergistically contribute to the development of diabetes in NOD mice.

Keywords IFN- $\gamma \cdot$ IL-17 $\cdot$ Lymphopenia $\cdot$ NOD mice $\cdot$ Th17 $\cdot$ Type 1 diabetes

H. Yamasaki

Center for Health and Community Medicine, Nagasaki University,

Nagasaki, Japan

L. Yu

Barbara Davis Center for Diabetes, UCHSC,

Aurora, CO, USA

Y. Iwakura

Center for Experimental Medicine and Systems Biology,

Institute of Medical Science, University of Tokyo, Tokyo, Japan

Y. Nagayama

Department of Molecular Medicine, Nagasaki University Graduate

School of Biomedical Sciences, Nagasaki, Japan 


$\begin{array}{ll}\text { Abbreviations } \\ \text { CFA } & \text { Complete Freund's adjuvant } \\ \text { Cy } & \text { Cyanine } \\ \text { IAA } & \text { Insulin autoantibody } \\ \text { IFN- } \gamma \text { R } & \text { IFN- } \gamma \text { receptor } \\ \text { PE } & \text { Phycoerythrin } \\ \text { PMA } & \text { Phorbol 12-myristate 13-acetate } \\ \text { SCID } & \text { Severe combined immunodeficiency } \\ \text { SPC } & \text { Splenocyte } \\ \text { TCR-Tg } & \text { T cell receptor transgenic } \\ \text { Teff } & \text { Effector T cell } \\ \text { Th } & \text { T helper type } \\ \text { Treg } & \text { Regulatory T cell } \\ \text { wt } & \text { Wild-type }\end{array}$

\section{Introduction}

Type 1 diabetes results from the autoimmune destruction of pancreatic beta cells mediated by $\mathrm{CD} 4^{+}$and $\mathrm{CD} 8^{+} \mathrm{T}$ cells [1]. Thelper type (Th) 1 cells are believed to play a key role in the pathogenesis of type 1 diabetes in the NOD mouse model of diabetes, because pancreatic islet-infiltrating mononuclear cells and diabetogenic $\mathrm{T}$ cell clones derived from NOD islets show strong expression of Th1 cytokines [2-5]. However, an unresolved issue is why the elimination of Th1 cytokines or their signalling molecules, including IFN- $\gamma$, IL-12 and IFN- $\gamma$ receptor (IFN- $\gamma$ R), does not reduce the incidence of diabetes in NOD mice [6-10].

Th17 cells that produce IL-17 have been shown to play important roles in mouse models of several autoimmune diseases including experimental autoimmune encephalomyelitis, rheumatoid arthritis and autoimmune thyroiditis and others that had previously been thought to be Th1-dominant [11-16]. In the context of NOD mice, there are data suggesting that Th17 cells play a pathogenic role in type 1 diabetes development [17]. The administration of GAD peptide inserted into immunoglobulin molecules inhibited diabetes development, dependent on the induction of splenic IFN- $\gamma$ which inhibited IL-17 production [18], and treatment with neutralising antibodies to IL-17 prevented the development of diabetes in NOD mice [19]. However, similarly to IFN- $\gamma$ knockout in NOD mice, an IL-17 knockdown NOD line created by directly introducing a short hairpin RNA construct did not show altered diabetes susceptibility [20].

The differentiation of naive $\mathrm{CD}^{+} \mathrm{T}$ cells to effector $\mathrm{T}$ cells (Teffs) or regulatory $\mathrm{T}$ cells (Tregs) is more plastic than previously thought [21]. Th17 cells have been shown to be converted into Th1 cells in a transfer model of colitis [22]. In type 1 diabetes, diabetogenic $\mathrm{BDC} 2.5 \mathrm{CD}^{+} \mathrm{T}$ cells polarised in vitro into the Th17 cell phenotype are converted into Th1-like cells after adoptive transfer into NOD/severe combined immunodeficiency (SCID) mice, ultimately causing beta cell destruction and diabetes [23, 24]. Thus, it is possible that the conversion of Th17 cells into Th1 cells or Th1/Th17 cells coexpressing Th1 and Th17 cytokines in the pancreatic islets might counteract the disease inhibition by eliminating a single cytokine gene from the NOD mice.

To address this issue we produced NOD mice genetically deficient in both IL-17 and IFN- $\gamma$ R, and we evaluated insulitis/diabetes development in comparison with that in IL-17 single-deficient NOD background mice.

\section{Methods}

Mice NOD and NOD/SCID mice were purchased from Clea Japan (Tokyo, Japan). IL-17-deficient NOD mice were generated as described (originally on a $129 / \mathrm{Sv} \times \mathrm{C} 57 \mathrm{BL} / 6$ genetic background) [25]. IFN- $\gamma$ R-deficient NOD mice were obtained from O. Kanagawa (Laboratory for Autoimmune Regulation, RIKEN Research Center for Allergy and Immunology, Yokohama, Japan). All animal experiments described in this study were conducted with the approval of the institutional animal experimentation committee in accordance with the Guidelines for Animal Experimentation of Nagasaki University.

Establishment of IL-17 single-deficient and IL-17/IFN- $\gamma R$ double-deficient NOD mice IL-17-deficient mice were backcrossed with NOD mice for eight successive generations. An analysis of the microsatellite markers of the diabetes susceptibility (Idd1-14) loci by PCR of the tail DNA as described [26] showed that the mice were homozygous for all of the NOD alleles (namely, $I l 17^{-1}$ NOD mice). IFN- $\gamma$ R-deficient NOD mice were crossed with $I l 17^{/-}$NOD mice, and the resulting F1 hybrids, $I l 17^{+-} /$Ifngr $I^{+/-}$NOD mice, were intercrossed to produce IL-17 single-deficient $\left(I l 17^{-/-} /\right.$Ifngr $\left.I^{+/+}\right)$,

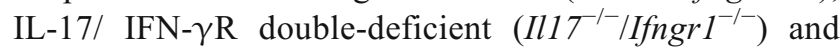
wild-type (wt; $I l 17^{+/+} / I f n g r I^{+/+}$) NOD littermate mice. Only female mice were used for the present study. These mice were selected by PCR analysis of tail DNA as described [25, 26]. Tail DNA was extracted with the REDExtract-N-Amp Tissue PCR kit (Sigma, St Louis, MO, USA).

Monitoring for spontaneous diabetes Blood glucose levels were monitored using the One-touch Ultra (Johnson \& Johnson, Tokyo, Japan). Mice with blood glucose levels $>13.9 \mathrm{mmol} / \mathrm{l}$ in two consecutive measurements were considered diabetic.

Measurement of insulin autoantibodies Mice were bled at 8, 12 and 16 weeks of age, and serum samples were obtained and stored at $-20^{\circ} \mathrm{C}$ until the antibody assay. The levels of insulin autoantibodies (IAAs) were evaluated by a 96-well filtration plate micro-IAA assay, as described [27]. The index value of 0.01 was selected as 
the cut-off limit at the 100th percentile of $50 \mathrm{Balb} / \mathrm{c}$ and C57BL/6 mouse samples.

Histology Pancreatic sections were histologically analysed by fixing the tissue specimens in $10 \%$ formalin and staining the paraffin-embedded samples with haematoxylin and eosin. A minimum of 30 islets from each mouse were examined microscopically by two different observers for the presence of insulitis. The severity of insulitis was scored as follows: 0 , no lymphocytic infiltration; 1 , lymphocytic infiltration occupying $<25 \%$ of the total islet cell area; 2 , lymphocytic infiltration occupying $25-49 \%$ of the total islet cell area; 3, lymphocytic infiltration occupying $50-75 \%$ of the total islet cell area; 4 , lymphocytic infiltration occupying $>75 \%$ of the total islet cell area, or small retracted islets.

Adoptive transfer experiments Donor $\mathrm{CD} 4^{+} \mathrm{CD} 25^{-} \mathrm{T}$ cells were purified from the spleens of 10- or 18-week-old prediabetic mice, and $\mathrm{CD}^{+} \mathrm{T}$ cells were purified from 15- to 22-week-old newly diabetic mice, using magnetic bead cell sorting (Miltenyi Biotec, Bergisch-Gladbach, Germany). Purified $\mathrm{CD}^{+} \mathrm{CD} 25^{-} \mathrm{T}$ cells or $\mathrm{CD} 4^{+} \mathrm{T}$ cells were adoptively transferred into 8- to 10-week-old NOD/SCID mice, and the recipient mice were monitored for blood glucose twice weekly after the adoptive transfer.

Flow cytometric analysis Single cell suspensions of splenocytes (SPCs) were prepared from spleens of NOD mice at 10 weeks of age. Red cells were lysed in ammonium chloride buffer. For surface staining, cells were stained for $20 \mathrm{~min}$ with the corresponding fluorescently labelled antibodies against surface molecules: CD3e (145-2C11), CD4 (GK1.5), CD8 (53-6.7), B220 (RA3-6B2), CD44 (IM7), CD62L (MEL-14) (all from eBioscience, San Diego, CA, USA). For the intracellular cytokine staining, the prepared SPCs were stimulated with $50 \mathrm{ng} / \mathrm{ml}$ phorbol 12-myristate 13-acetate (PMA) and $500 \mathrm{ng} / \mathrm{ml}$ ionomycin (both from Sigma) in the presence of $2 \mu \mathrm{mol} / 1$ monensin for $5 \mathrm{~h}$. Thereafter, the cells were stained with allophycocyanin-cyanine (Cy)5-conjugated anti-CD4, followed by intracellular IFN- $\gamma$ and IL-17 staining with phycoerythrin (PE)-Cy7-conjugated anti-IL-17 (eBio17B7) and peridinin chlorophyll protein complexCy5.5-conjugated anti-INF- $\gamma$ (XMG1.2) antibodies (all from eBioscience). Alternatively, the cells were resuspended with PBS and stained with FITC-conjugated anti-CD4 and PE-conjugated anti-CD25 (PC61) (BD Biosciences, San Diego, CA, USA), followed by intracellular Foxp3 staining with PE-Cy5-conjugated anti-FoxP3 (FJK16 s; Foxp3 staining kit; eBioscience). All cells were analysed on a FACSCanto II flow cytometry system using FACS Diva software (BD Biosciences).
Statistical analysis Group differences were analysed by Mann-Whitney $U$ test or Student's $t$ test, and differences between the Kaplan-Meier survival curves were estimated by the logrank test using SPSS Version 11.0 J (Chicago, IL, USA). The $\chi^{2}$ test was used to compare the incidence of diabetes at each week of age. $p$ values $<0.05$ were considered significant. The severity of the insulitis was analysed by a ridit analysis, and $t$ levels higher than 1.96 or lower than -1.96 were considered significant.

\section{Results}

Diabetes and insulitis in the IL-17-deficient and IL-17/IFN$\gamma$-deficient NOD mice In our colony, $\sim 75 \%$ of the female and $30-40 \%$ of the male NOD mice usually develop diabetes by 48 weeks. A life-table analysis revealed that the onset of spontaneous diabetes in the Ill ${ }^{/-} /$Ifngr $I^{+/+}$NOD mice was significantly delayed compared with the onset in wt NOD littermate mice $(p<0.05$ by the logrank test). The weekly incidence of diabetes in the $I l 17^{-1-} /$ Ifngr $I^{+/+} \mathrm{NOD}$ mice was also significantly lower from 15 to 24 weeks of age than that in wt NOD mice ( $p<0.05$ by $\chi^{2}$ test). However, the cumulative incidence of diabetes at 50 weeks of age in the $I l 17^{-/} /$Ifngr $1^{+/+}$NOD mice was similar to that in the wt mice ( $80.0 \%$ vs $85.7 \%$, respectively) (Fig. 1a). As for the IL-17/IFN- $\gamma$ R double-deficient NOD mice, the onset of diabetes was significantly suppressed compared with that in the $I l 17^{-/-} /$Ifngr $1^{+/+}$NOD mice and wt NOD mice $\left(I l 17^{-1} /\right.$ Ifngr $1^{-/-}$vs $I l 17^{-/} /$Ifngr $I^{+/+}$and vs wt, $p=0.01$ by the logrank test). The weekly incidence of diabetes in the Ill ${ }^{-1}$ IIfngr $I^{-1-}$ NOD mice was significantly lower from 26 to 50 weeks of age compared with that in the $I l 17^{1-} / I$ Ifngr $I^{+/+}$ NOD mice $\left(p<0.05\right.$ by $\chi^{2}$ test) and from 16 until 50 weeks of age compared with that in wt NOD mice ( $p<0.05$ by $\chi^{2}$ test). The cumulative incidence of diabetes at 50 weeks of age in the Ill $17^{/-}$Iffngr $1^{-/-}$NOD mice was $43.8 \%$, and disease suppression was maintained throughout the entire lifespan (Fig. 1a).

We next compared the severity of insulitis at 12 and 18 weeks of age in the $I l 17^{-1} /$ Ifngr $1^{-/-}, I l 17^{-1-} /$ Ifngr $1^{+/+}$ and wt NOD mice. The severity of insulitis was significantly attenuated in the $I l 17^{-/-} /$Ifngr $I^{-/-}$and $I l 17^{-1-} /$ Ifngr $I^{+/+} \mathrm{NOD}$ mice compared with that in the wt mice (by ridit analysis). However, there were no significant differences between the $I l 17^{-1} /$ Ifngr $I^{-/-}$and $I l 17^{-/} /$Ifngr $I^{+/+}$NOD mice at 12 or 18 weeks of age (Fig. 1b,c).

IAA levels in the IL-17-deficient and IL-17/IFN- $\gamma$ R-deficient NOD mice We then determined the levels of IAAs in the $I l 17^{-1-} /$ Ifngr $I^{-/-}, I l 17^{-1-} /$ Ifngr $I^{+/+}$and wt NOD mice at 8,12 and 16 weeks of age. Despite the suppression of insulitis/diabetes development in the $I l 17^{-1} /$ Ifngr $I^{-/-}$and $I l 17^{-/-} /$Ifngr $I^{+/+}$mice, the serum levels of IAAs and 
a

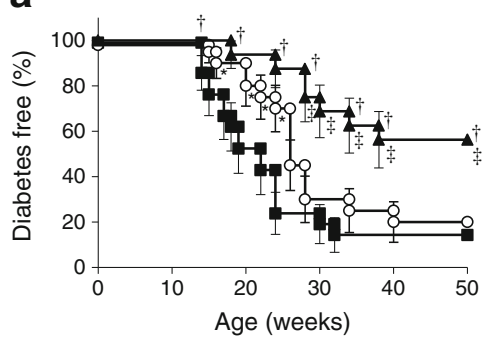

b

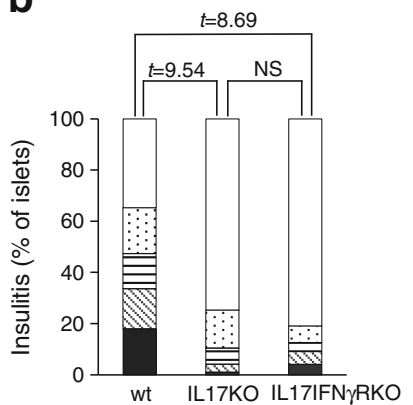

C

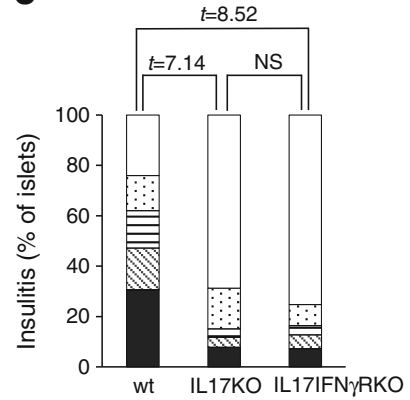

Fig. 1 Diabetes and insulitis in the IL-17-deficient and IL-17/IFN- $\gamma$ Rdeficient NOD mice. (a) Incidence of diabetes in wt NOD mice (squares, $n=21$ ), $I l 17^{-1-} /$ Ifngr $I^{+/+}$NOD mice (circles, $n=20$ ) and $I l 17^{-1} /$ Ifngr $1^{-1-}$ NOD mice (triangles, $n=16$ ). The $\chi^{2}$ test was used to compare the incidence of diabetes at each week of age $\left({ }^{*} p<0.05\right.$, Ill $17^{-/} /$Ifngr $1^{+/+}$vs wt; ${ }^{\dagger} p<0.05$, Il $17^{-/} /$Ifngr $I^{-/-}$vs wt; ${ }^{\ddagger} p<0.05$, $I l 17^{-1} /$ Ifngr $I^{+/+}$vs $I l 17^{-1} /$ Ifngr $I^{-/-}$). The severity of insulitis in 12week-old (b) or 18-week-old (c) wt NOD mice $(n=5), I l 17^{1-} / I f n g r I^{+/+}$ NOD mice $(n=5)$ and $I l 17^{-1} /$ Ifngr $I^{-1-}$ NOD mice $(n=5)$. KO, knockout. The severity of insulitis was scored as described in the Methods section. Levels of insulitis: 0 (white), 1 (dotted), 2 (horizontal stripes), 3 (diagonal stripes) and 4 (black). A $t$ ridit analysis was used, and $t$ levels of higher than 1.96 or lower than -1.96 were considered significant

percentage of mice positive for IAAs did not significantly differ between the $I l 17^{-1} /$ Ifngr $1^{-/}$and wt NOD mice or between the $I l 17^{-1-} / I f n g r I^{+/+}$and wt mice, at all ages (data not shown).

Adoptive transfer of the CD4 $4^{+}$Teffs from $I l 17^{--}$NOD mice into NOD/SCID mice Our aforementioned data suggest that IL-17 may play an important role in the development of insulitis. However, it is possible that IL-17 is associated with diabetes development only in younger NOD mice and not in older mice, since disease inhibition by IL-17 single deficiency was not maintained past 24 weeks of age. We therefore compared the diabetogenicity of $\mathrm{CD}^{+}$Teffs from $I l 17^{-1-}$ and wt NOD mice at different ages to adoptively transfer diabetes into NOD/SCID mice.

The adoptive transfer of purified $\mathrm{CD} 4^{+} \mathrm{CD} 25^{-}$Teffs from 10 -week-old non-diabetic $I l 17^{-1-}$ mice resulted in significantly delayed disease onset compared with transfer from the corresponding wt NOD mice (Fig. 2a). No significant differences in disease development were seen in NOD/SCID mice after adoptive transfer with $\mathrm{CD} 4^{+} \mathrm{CD} 25^{-} \mathrm{T}$ cells from 18-week-old non-diabetic $I l 17^{-1}$ or wt NOD mice (Fig. 2b), or with $\mathrm{CD}^{+} \mathrm{T}$ cells from 15 - to 22 -week-old newly diabetic $I l 17^{-1-}$ or wt NOD mice (Fig. 2c).

Flow cytometric analysis for $C D 4^{+} T$ cells in the IL-17deficient and IL-17/IFN- $\gamma$ R-deficient NOD mice We first counted lymphocyte numbers and found that 10 -week-old $I l 17^{-1-}$ Iffngr $1^{-1-}$ NOD mice had significantly reduced numbers of lymphocytes including $\mathrm{CD}^{+}, \mathrm{CD}^{+}$and $\mathrm{CD} 8^{+}$
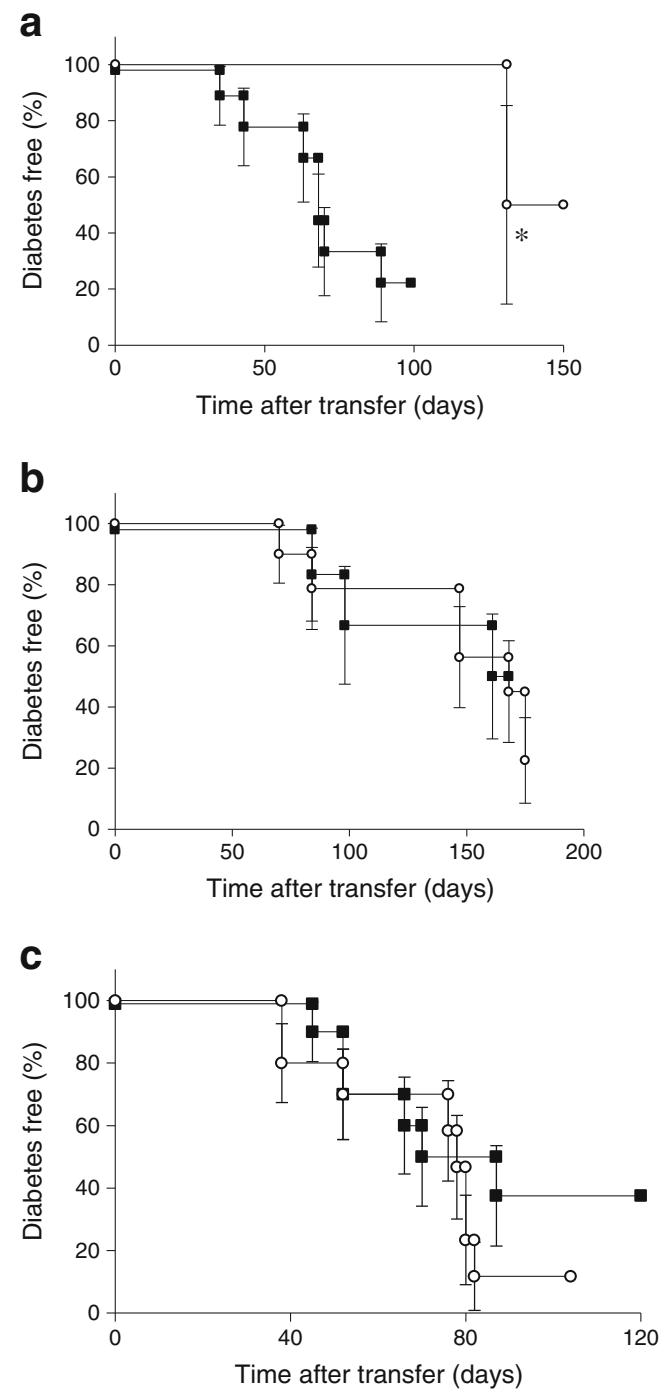

Fig. 2 Adoptive transfer of $\mathrm{CD}^{+}$Teffs into 8- to 10 -week-old NOD/ SCID mice. (a) $\mathrm{CD} 4^{+} \mathrm{CD} 25^{-} \mathrm{T}$ cells $\left(1 \times 10^{7}\right)$ from 10 -week-old nondiabetic $I l 17^{-1-}$ NOD mice (circles, $n=5$ ) or wt NOD mice (squares, $n=9$ ) were transferred into recipient NOD/SCID mice. ${ }^{*} p=0.03$ by the logrank test. (b) $\mathrm{CD}^{+} \mathrm{CD} 25^{-} \mathrm{T}$ cells $\left(1 \times 10^{7}\right)$ from 18 -week-old non-diabetic $I l 17^{-1-}$ NOD mice (circles, $n=10$ ) or wt NOD mice (squares, $n=6$ ) were transferred into recipient NOD/SCID mice. $p=0.84$ by the logrank test. (c) $\mathrm{CD}^{+}$cells $\left(5.5 \times 10^{6}\right)$ from 15 - to 22 -week-old freshly diabetic $1 l 17^{-1-}$ NOD mice (circles, $n=10$ ) or wt NOD mice (squares, $n=10$ ) were transferred into recipient NOD/SCID mice. $p=0.48$ by the logrank test 
$\mathrm{T}$ cells and $\mathrm{B}$ cells in the spleen, and the numbers were almost half or less than half of those in the $I l 17^{-1-} / \mathrm{Ifngrl} \mathrm{I}^{+/+}$ or wt NOD mice. The percentages of $\mathrm{CD}^{+}{ }^{+} \mathrm{T}$ cells, $\mathrm{CD} 8^{+} \mathrm{T}$ cells and B cells in the SPCs were not significantly different among the three groups (Table 1). As for the $\mathrm{CD}^{+} \mathrm{T}$ cell fraction, the production of cytokines was evaluated by intracellular cytokine staining after stimulation with PMA and ionomycin for $5 \mathrm{~h}$. The percentages of IFN- $\gamma$-producing cells did not significantly differ among the three groups, although the number in the $I l 17^{-1-} / \mathrm{Ifngr} \mathrm{I}^{-/-}$mice tended to be decreased compared with the other groups $(3.22 \pm 1.37 \%$ vs $4.42 \pm 0.90 \%$ in $I l 17^{-1-} /$ Ifngr $I^{+/+}$mice $[p=0.11]$ vs $4.19 \pm$ $0.66 \%$ in wt mice $[p=0.11]$, respectively) (Fig. 3a-d). IL17-producing cells among the $\mathrm{CD} 4^{+} \mathrm{T}$ cells were observed only in wt mice $(0.34 \pm 0.11 \%)$ as expected, and doublepositive cells with IL-17 and IFN- $\gamma$ were not observed in any of the groups (Fig. 3a-c,e).

We next determined the activation markers including CD44 and CD62L on $\mathrm{CD}^{+} \mathrm{T}$ cell and Treg populations without stimulation. No significant differences were found in the level of activation markers on the $\mathrm{CD} 4^{+} \mathrm{T}$ cells among the three groups (Fig. $4 \mathrm{a}-\mathrm{c}, \mathrm{g}$ ). As for Tregs, the percentage of $\mathrm{CD} 25^{+} \mathrm{Foxp}^{+}$cells to $\mathrm{CD} 4^{+} \mathrm{T}$ cells was significantly higher in the $I l 17^{-1-} /$ Ifngr $1^{-1-}$ mice than in the Ill ${ }^{/-} /$Ifngr $I^{+/+}$mice $(6.8 \pm 0.96 \%$ vs $4.7 \pm 0.54 \%, p<0.01)$ and in the wt mice (vs $5.4 \pm 0.32 \%, p<0.05$ ) (Fig. $4 d-$ f,h). The preferential increase in Tregs may be a systemic phenotype, since a higher percentage of $\mathrm{CD} 25^{+}$cells to $\mathrm{CD} 4^{+}$ $\mathrm{T}$ cells was observed in mesenteric lymph nodes or pancreatic draining lymph nodes (data not shown).

\section{Discussion}

In this study, we first determined the impact of the genetic deletion of IL-17, a potent proinflammatory cytokine, in the NOD mouse to investigate whether IL-17 is involved in the pathogenesis of type 1 diabetes. Our results show that the severity of insulitis was attenuated in both the IL-17 singledeficient and IL-17/IFN- $\gamma$ R double-deficient NOD mice, with no significant difference between these two types of mice, indicating that IL-17 rather than IFN- $\gamma$ signalling plays a key role in the build-up of the inflammatory infiltrate into islets in NOD mice, as is the case for numerous other autoimmune diseases (Fig. 1b,c) [11-16]. This result is also consistent with the finding of Martin-Orozco et al that in vitro-polarised Th17 cells derived from BDC2.5 T cell receptor transgenic (TCR-Tg) NOD mice transfer extensive insulitis, but do not produce diabetes in newborn NOD mice [23].

Regarding the development of diabetes, we found that the onset of diabetes was significantly delayed in the IL-17 single-deficient NOD mice, although they remained susceptible to longstanding diabetes, which is consistent with the report by Joseph et al [20] (Fig. 1a). In the different line of IL-17 single-deficient NOD mice (original $1 l 17^{-1-} \mathrm{NOD}$ mice) $(n=47)$ and the wt littermate control mice $(n=44)$, we observed the same delayed-onset result in $I l 17^{-1-}$ NOD mice (vs control, $p<0.05$ by the logrank test) (electronic supplementary material [ESM] Fig. 1).

Previous studies have demonstrated that the phenotype of delayed onset in IFN- $\gamma$ R-deficient NOD mice is due to the presence of 129-derived genes closely linked to the knockout gene rather than to a lack of the target gene [10, 28]. However, our mapping study with polymorphic markers on chromosome 1 distinguishing NOD from the 129 alleles showed that the maximum interval of the 129-derived genes surrounding the $1117 a$ gene was less than $1 \mathrm{cM}$ (ESM Fig. 2), and there are no identified insulin-dependent diabetes mellitus loci in this region, suggesting that the resistance to the development of insulitis and diabetes in the $I l 17^{-1}$ NOD mice is attributable to the lack of IL-17 rather than to the influence of the 129-derived genes.

The phenotype of delayed onset in the IL-17 singledeficient NOD mice indicates that IL-17 might participate in the pathogenesis of the early phase of the development of diabetes. This hypothesis was verified by our adoptive transfer study, which showed the successful adoptive transfer of diabetes by $\mathrm{CD} 4^{+} \mathrm{CD} 25^{-}$Teffs from younger non-diabetic wt mice but not by those from the IL-17 single-deficient NOD

Table 1 Numbers of T cells $\left(\mathrm{CD} 4^{+}, \mathrm{CD} 8^{+}\right)$and B cells in the SPCs

\begin{tabular}{|c|c|c|c|c|c|}
\hline \multirow[t]{2}{*}{ Mice } & \multirow[t]{2}{*}{ Total cell number $\left(\times 10^{6}\right)$} & \multicolumn{4}{|l|}{$\begin{array}{l}\text { Cell number }\left(\times 10^{6}\right) \\
(\% / \mathrm{SPCs})\end{array}$} \\
\hline & & $\mathrm{CD}^{+}$ & $\mathrm{CD} 4^{+}$ & $\mathrm{CD}^{+}$ & $\mathrm{B} 220^{+}$ \\
\hline wt $(n=5)$ & $63.4 \pm 9.7$ & $27.0 \pm 4.8(42.7 \pm 5.1)$ & $18.7 \pm 3.4(29.4 \pm 3.5)$ & $5.8 \pm 0.9(9.2 \pm 1.4)$ & $16.2 \pm 1.6(25.7 \pm 1.8)$ \\
\hline 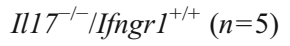 & $63.4 \pm 8.3$ & $24.7 \pm 3.0(39.2 \pm 5.2)$ & $16.2 \pm 2.6(25.9 \pm 4.8)$ & $5.4 \pm 0.5(8.6 \pm 0.9)$ & $15.4 \pm 1.1(24.7 \pm 3.3)$ \\
\hline$I l 17^{-1} /$ Ifngr $I^{-/-}(n=5)$ & $26.0 \pm 12.0^{*}$ & $12.2 \pm 6.3 * *(46.1 \pm 5.6)$ & $8.4 \pm 4.3^{* *}(32.1 \pm 4.5)$ & $2.4 \pm 1.4 * *(9.0 \pm 1.4)$ & $6.5 \pm 2.8^{*}(25.1 \pm 2.2)$ \\
\hline
\end{tabular}

The results are shown as means $\pm \mathrm{SD}$

${ }^{*} p<0.001,{ }^{* *} p<0.005$ vs wt or $I l 17^{/-} /$Ifngr $I^{+/+}$ 

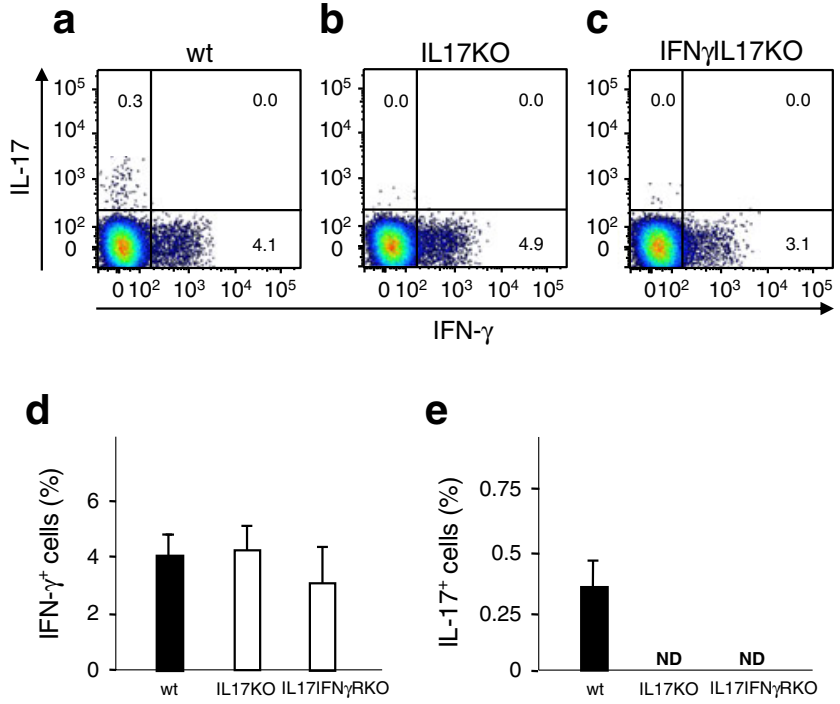

Fig. 3 IFN- $\gamma$ positive or IL-17 positive cells in CD4 $4^{+}$SPCs in the IL-17deficient and IL-17/IFN- $\gamma$ R-deficient NOD mice. SPCs were prepared, stimulated with PMA and ionomycin for $5 \mathrm{~h}$, stained for cell surface CD4 and intracellular IFN- $\gamma$ and IL-17, and analysed with flow cytometry (ac). Representative staining of $\mathrm{CD}^{+}$SPCs for intracellular IFN- $\gamma$ and/or IL-17. (d,e) Numeration of Th1 and Th17 cells, respectively. The data are means $\pm \mathrm{SD}(n=5)$. KO, knockout; $\mathrm{ND}$, not detected

mice of the same age (Fig. 2a). However, such attenuation of diabetes development by IL-17-deficient diabetogenic T cells was no longer seen after a similar transfer of the same cells derived from older non-diabetic or diabetic mice (Fig. 2b,c). Taken together, the present results suggest that IL-17 participates in the pathogenesis of the early phase of the development of diabetes, but elimination of IL-17 could be readily dispensable in the late phase of diabetes.

In vitro-polarised Th17 cells derived from BDC2.5 TCRTg NOD mice do not transfer diabetes in newborn NOD mice but do transfer diabetes in immune-deficient hosts through conversion into Th1 cells or Th1/Th17 cells coexpressing Th1 and Th17 cytokines [23, 24]. We hypothesised that such a conversion of Th17 into Th1 cells or Th1/Th17 cells may have compensated for the disease inhibition by IL-17 single deficiency in NOD mice in the present study. To test our hypothesis, we also evaluated the impact of the genetic deletion of both IL-17 and IFN- $\gamma$ signalling in NOD mice to determine whether such a double deficiency could clearly suppress disease. As hypothesised, IL-17/IFN- $\gamma$ R double deficiency significantly suppressed the longstanding incidence of diabetes compared with IL17 single deficiency in NOD mice (Fig. 1a). These results indicate that Th1 and Th17 cytokines may synergistically contribute to the development of diabetes in NOD mice, since IFN- $\gamma$ R-deficient NOD mice exhibit minimal or no inhibition of disease $[10,28]$.

We fortuitously found that IL-17/IFN- $\gamma$ R doubledeficient NOD mice had a severe lymphopenic phenotype.
A previous study demonstrated that wt NOD mice have mild lymphopenia compared with a non-autoimmune strain, and, as a result, compensatory homeostatic expansion of $\mathrm{T}$ cells generates anti-islet autoimmunity resulting in the development of diabetes [29]. In contrast, NOD mice harbouring a C57BL/6-derived Idd3 genetic interval (which encodes the Il2 and Il21 genes) (NOD.Idd3 mice) are disease-resistant and not lymphopenic. It has recently been shown that naive $\mathrm{T}$ cells from NOD mice exhibit a greater propensity to differentiate into Th17 cells than those from NOD.Idd3 mice, and IL-21 signalling in antigen-presenting cells plays a central role in such Th17 cell development [30].

On the other hand, several studies have demonstrated that diabetes susceptibility and protection in NOD mice correlate with lymphopenia and homeostatic expansion under a variety of experimental conditions. Thymectomy at weaning or treatment with cyclophosphamide, which causes lymphocyte apoptosis, accelerates diabetes onset in NOD mice
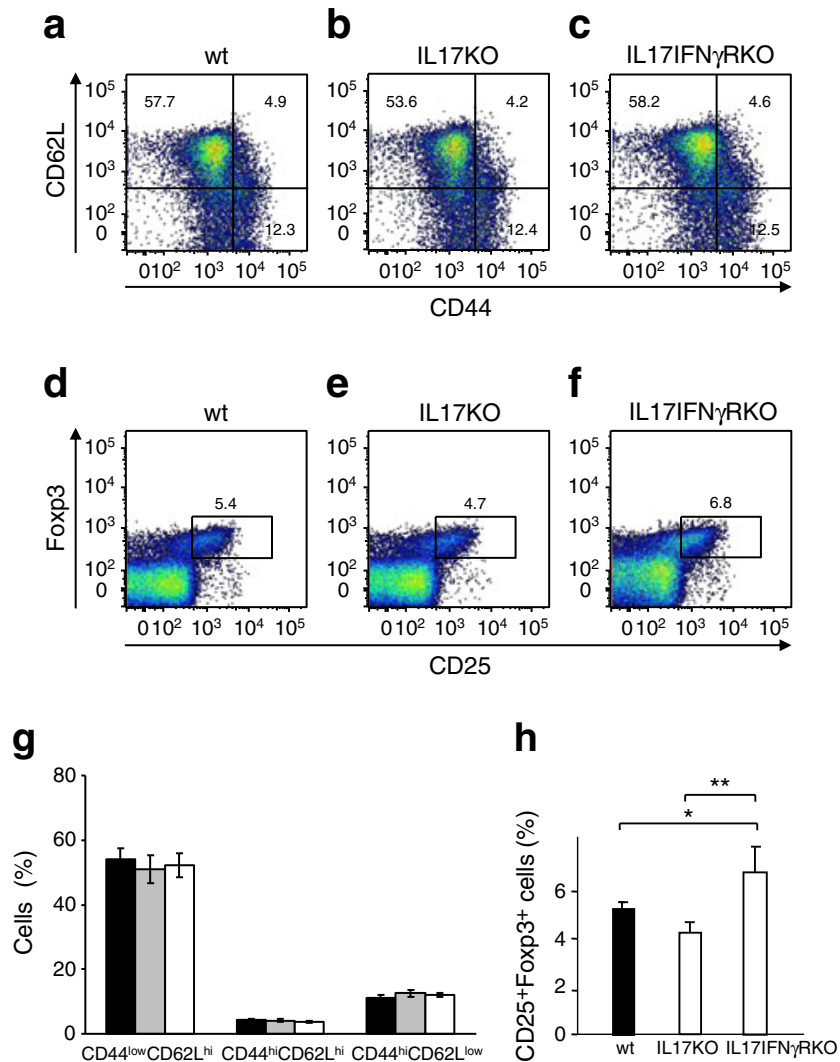

Fig. 4 Activation markers and $\mathrm{CD} 25^{+}$Foxp $3^{+}$cells in $\mathrm{CD} 4^{+}$SPCs. Unstimulated SPCs were stained for cell surface CD4, CD62L, CD44 and CD25, and intracellular Foxp3 and analysed with flow cytometry. Representative staining of CD4 ${ }^{+}$SPCs for $(\mathbf{a}-\mathbf{c}) \mathrm{CD} 62 \mathrm{~L}$ and CD44 and (d-f) CD25 and Foxp3. Numeration of (g) each CD44 ${ }^{\text {low }}$ CD62L ${ }^{\text {hi }}$, $\mathrm{CD} 44^{\mathrm{hi}} \mathrm{CD} 62 \mathrm{~L}^{\mathrm{hi}}$ and $\mathrm{CD} 44^{\mathrm{hi}} \mathrm{CD} 62 \mathrm{~L}^{\text {low }}$ cells in wt NOD mice (black bar), $I l 17^{-1} /$ Ifngr $1^{+/+}$NOD mice (solid grey) and $I l 17^{-1-} /$ Ifngr $1^{-1}$ NOD mice (white bar) and (h) $\mathrm{CD} 25^{+} \mathrm{Foxp}^{+}$cells. The data are mean $\pm \mathrm{SD}(n=5)$, and group differences were analysed by MannWhitney $U$ test. ${ }^{*} p<0.05,{ }^{* *} p<0.01$. KO, knockout 
$[31,32]$. In contrast, immunisation with complete Freund's adjuvant (CFA) increases $\mathrm{T}$ cell numbers and protects NOD mice from diabetes $[29,33]$. Mori et al have reported that IFN- $\gamma \mathrm{R}$ deficiency abrogates cyclophosphamide-induced acceleration of diabetes and CFA-mediated protection in NOD mice $[34,35]$. Thus, Th17 cell development and IFN- $\gamma$ signalling may play a critical role in diabetes susceptibility mediated by lymphopenia-induced homeostatic expansion in NOD mice, although the precise kinetics and mechanisms of severe lymphopenia in these mice are still being elucidated.

We also found that double-deficient NOD mice had a preferential increase in Tregs among $\mathrm{CD} 4^{+}$splenic $\mathrm{T}$ cells. Several recent findings highlight the plasticity within the $\mathrm{CD}^{+}{ }^{+}$Th cell population including Th1, Th2, Th17 and Tregs, and Th17 cells and Tregs are more plastic than Th1/Th2 cells [21]. Networks of cytokines are critical for determining $\mathrm{CD}^{+} \mathrm{T}$ cell fates and effector cytokines [36]. For example, Bertin-Maghit et al clearly demonstrated that systemic overproduction of IL-1 $\beta$ in 6- to 16 -week-old NOD mice impairs Treg function and promotes the Treg to Th17 conversion [37]. A pair of studies showed that Th17 cells generated ex vivo or in vitro can be converted into the Th1 phenotype by combined IFN- $\gamma$ and IL-12 signalling through epigenetic processes $[38,39]$. As described above, in vitro-polarised Th17 cells are readily reprogrammed into other $\mathrm{T}$ cell lineages on transfer into lymphopenic hosts [23, 40]. Of note, treatment with cyclophosphamide not only fails to accelerate diabetes but also confers permanent protection against diabetes by the preferential generation of Tregs in IFN- $\gamma \mathrm{R}$-deficient NOD mice [34]. It is possible that IFN- $\gamma \mathrm{R}$ deficiency under lymphopenic conditions inhibits such a Th shift from Th1 to Th17 or from Tregs to another Teff lineage, resulting in a preferential increase in the Treg population and disease resistance in our doubledeficient NOD mice.

Thus, we have here demonstrated that IL-17/Th17 participates in the development of insulitis and that both IL-17 and IFN- $\gamma$ signalling may synergistically contribute to the Teff/Treg balance to Teffs during homeostasis expansion and the subsequent development of diabetes in NOD mice.

From the clinical point of view, the therapeutic efficacy of the inhibition of Th17 cells in some autoimmune diseases has been demonstrated $[18,19]$. It has been reported that children with new-onset type 1 diabetes have an increased proportion of memory $\mathrm{CD}^{+}$cells that have increased IL-17 secretion, suggesting that upregulation of Th17 immunity is associated with human type 1 diabetes [41, 42]. This implies a novel potential therapeutic strategy for human type 1 diabetes based on the control of IL-17 immunity. However, the results presented in the present study indicate that a single blockade of an effector cytokine such as IL-17 or IFN- $\gamma$ readily compensates for the Th shift from Tregs to effector Th lineage through multiple networks of cytokines. The appropriate timing or therapeutic strategy for inhibiting the Treg/Teff conversion - such as a combination blockade of multiple cytokines or transcriptional factors such as the Janus kinase (JAK)-signal transducers and activator of transcription (STAT) pathway, Runx3 and IRF-4-should be carefully considered with the goal of preventing or delaying the development of type 1 diabetes [36].

Acknowledgements We thank O. Kanagawa for providing IFN- $\gamma$ Rdeficient NOD mice and M. Motomura and Y. Kataoka for their technical assistance. G. S. Eisenbarth, who was executive director of the Barbara Davis Center for Diabetes, contributed greatly to the early experiments of the study before his untimely death.

Funding This work was supported by research grants from the Japan Society for the Promotion of Science (Nos 24591334, 21591143, 23791036 and 22790865).

Duality of interest The authors declare that there is no duality of interest associated with this manuscript.

Contribution statement All authors contributed to the conception and design of the study, acquisition, analysis and interpretation of data, and drafting and editing of the manuscript. All of the authors approved the final version of the manuscript. GK, MK and NA had full access to all of the data in the study and take responsibility for the integrity of the data and the accuracy of the data analysis.

\section{References}

1. Eisenbarth GS, Vardi P, Ziegler AG et al (1988) Lessons from the NOD mouse and BB rat: similarities and contrasts. In: Renold AE, Shafir E (eds) Frontiers in diabetes research: lessons from animal diabetes: II. John Libbey, London

2. Rabinovitch A, Suarez-Pinzon WL, Sorensen O, Bleackley RC, Power RF (1995) IFN-gamma gene expression in pancreatic isletinfiltrating mononuclear cells correlates with autoimmune diabetes in nonobese diabetic mice. J Immunol 154:4874-4882

3. Suarez-Pinzon W, Rajotte RV, Mosmann TR, Rabinovitch A (1996) Both CD4+ and CD8+ T cells in syngeneic islet grafts in NOD mice produce interferon- $\gamma$ during $\beta$-cell destruction. Diabetes 45:1350-1357

4. Haskins K, Wegmann D (1996) Diabetogenic T cell clones. Diabetes 45:1299-1305

5. Haskins K (2005) Pathogenic T cell clones in autoimmune diabetes: more lessons from the NOD mouse. Adv Immunol 87:123-162

6. Hultgren B, Huang X, Dybdal N, Stewart TA (1996) Genetic absence of $\gamma$-interferon delays but does not prevent diabetes in NOD mice. Diabetes 45:812-817

7. Serreze DV, Chapman HD, Post CM, Johnson EA, Suarez-Pinzon WL, Rabinovitch A (2001) Th1 to Th2 cytokine shifts in nonobese diabetic mice: sometimes an outcome, rather than the cause, of diabetes resistance elicited by immunostimulation. J Immunol 166:1352-1359

8. Trembleau S, Penna G, Gregori S et al (1999) Pancreas-infiltrating Th1 cells and diabetes develop in IL-12-deficient nonobese diabetic mice. J Immunol 163:2960-2968

9. Serreze DV, Post CM, Chapman HD, Johnson EA, Lu B, Rothman PB (2000) Interferon-gamma receptor signaling is dispensable in the development of autoimmune type 1 diabetes in NOD mice. Diabetes 49:2007-2011 
10. Kanagawa O, Xu G, Tevaarwerk A, Vaupel BA (2000) Protection of nonobese diabetic mice from diabetes by gene(s) closely linked to IFN-gamma receptor loci. J Immunol 164:3919-3923

11. Komiyama Y, Nakae S, Matsuki T et al (2006) IL-17 plays an important role in the development of experimental autoimmune encephalomyelitis. J Immunol 177:566-573

12. Nakae S, Nambu A, Sudo K, Iwakura Y (2003) Suppression of immune induction of collagen-induced arthritis in IL-17-deficient mice. J Immunol 171:6173-6177

13. Veldhoen M, Hocking RJ, Flavell RA, Stockinger B (2006) Signals mediated by transforming growth factor-beta initiate autoimmune encephalomyelitis, but chronic inflammation is needed to sustain disease. Nat Immunol 7:1151-1156

14. Sutton C, Brereton C, Keogh B, Mills KH, Lavelle EC (2006) A crucial role for interleukin (IL)-1 in the induction of IL-17producing $\mathrm{T}$ cells that mediate autoimmune encephalomyelitis. J Exp Med 203:1685-1691

15. Nakae S, Saijo S, Horai R, Sudo K, Mori S, Iwakura Y (2003) IL17 production from activated $\mathrm{T}$ cells is required for the spontaneous development of destructive arthritis in mice deficient in IL-1 receptor antagonist. Proc Natl Acad Sci U S A 100:5986-5990

16. Horie I, Abiru N, Nagayama Y et al (2009) T helper type 17 immune response plays an indispensable role for development of iodine-induced autoimmune thyroiditis in nonobese diabetic- $\mathrm{H} 2 \mathrm{~h} 4$ mice. Endocrinology 150:5135-5142

17. Haskins K, Cooke A (2011) CD4 T cells and their antigens in the pathogenesis of autoimmune diabetes. Curr Opin Immunol 23:739-745

18. Jain R, Tartar DM, Gregg RK et al (2008) Innocuous IFNgamma induced by adjuvant-free antigen restores normoglycemia in NOD mice through inhibition of IL-17 production. J Exp Med 205:207-218

19. Emamaullee JA, Davis J, Merani S et al (2009) Inhibition of Th17 cells regulates autoimmune diabetes in NOD mice. Diabetes 58:1302-1311

20. Joseph J, Bittner S, Kaiser FM, Wiendl H, Kissler S (2012) IL-17 silencing does not protect nonobese diabetic mice from autoimmune diabetes. J Immunol 188:216-221

21. Zhou L, Chong MM, Littman DR (2009) Plasticity of CD4+ T cell lineage differentiation. Immunity 30:646-655

22. Lee YK, Turner H, Maynard CL et al (2009) Late developmental plasticity in the $\mathrm{T}$ helper 17 lineage. Immunity 30:92-107

23. Martin-Orozco N, Chung Y, Chang SH, Wang YH, Dong C (2009) Th17 cells promote pancreatic inflammation but only induce diabetes efficiently in lymphopenic hosts after conversion into Th1 cells. Eur J Immunol 39:216-224

24. Bending D, de la Pena H, Veldhoen M et al (2009) Highly purified Th17 cells from BDC2.5NOD mice convert into Th1-like cells in NOD/SCID recipient mice. J Clin Invest 119:565-572

25. Nakae S, Komiyama Y, Nambu A et al (2002) Antigen-specific $\mathrm{T}$ cell sensitization is impaired in IL-17-deficient mice, causing suppression of allergic cellular and humoral responses. Immunity $17: 375-387$
26. Serreze DV, Chapman HD, Varnum DS et al (1996) B lymphocytes are essential for the initiation of $\mathrm{T}$ cell-mediated autoimmune diabetes: analysis of a new "speed-congenic" stock of NOD.Ig $\mu$ null mice. J Exp Med 184:2049-2053

27. Yu L, Robles DT, Abiru N et al (2000) Early expression of antiinsulin autoantibodies of humans and the NOD mouse: evidence for early determination of subsequent diabetes. Proc Natl Acad Sci U S A 97:1701-1706

28. Wang B, André I, Gonzalez A et al (1997) Interferon-gamma impacts at multiple points during the progression of autoimmune diabetes. Proc Natl Acad Sci U S A 94:13844-13849

29. King C, Ilic A, Koelsch K, Sarvetnick N (2004) Homeostatic expansion of $\mathrm{T}$ cells during immune insufficiency generates autoimmunity. Cell 117:265-277

30. Liu SM, Lee DH, Sullivan JM et al (2011) Differential IL-21 signaling in APCs leads to disparate Th17 differentiation in diabetes-susceptible NOD and diabetes-resistant NOD.Idd3 mice. $\mathrm{J}$ Clin Invest 121:4303-4310

31. Dardenne M, Lepault F, Bendelac A, Bach JF (1989) Acceleration of the onset of diabetes in NOD mice by thymectomy at weaning. Eur J Immunol 19:889-895

32. Harada M, Makino S (1982) Promotion of spontaneous diabetes in nonobese diabetes-prone mice by cyclophosphamide. Diabetologia 27:604-606

33. Sadelain MW, Qin H-Y, Lauzon J, Singh B (1990) Prevention of type I diabetes in NOD mice by adjuvant immunotherapy. Diabetes 39:583-589

34. Mori Y, Kato T, Kodaka T, Kanagawa EM, Hori S, Kanagawa O (2008) Protection of IFN-gamma signaling-deficient NOD mice from diabetes by cyclophosphamide. Int Immunol 20:1231-1237

35. Mori Y, Kodaka T, Kato T, Kanagawa EM, Kanagawa O (2009) Critical role of IFN-gamma in CFA-mediated protection of NOD mice from diabetes development. Int Immunol 21:1291-1299

36. Zhu J, Paul WE (2010) Heterogeneity and plasticity of T helper cells. Cell Res 20:4-12

37. Bertin-Maghit S, Pang D, O'Sullivan B et al (2011) Interleukin-1beta produced in response to islet autoantigen presentation differentiates T-helper 17 cells at the expense of regulatory T cells: implications for the timing of tolerizing immunotherapy. Diabetes 60:248-257

38. Lexberg MH, Taubner A, Albrecht I et al (2010) IFN-gamma and IL-12 synergize to convert in vivo generated Th17 into Th1/Th17 cells. Eur J Immunol 40:3017-3027

39. Bending D, Newland S, Krejci A, Phillips JM, Bray S, Cooke A (2011) Epigenetic changes at Il12rb2 and Tbx21 in relation to plasticity behavior of Th17 cells. J Immunol 186:3373-3382

40. Nurieva R, Yang XO, Chung Y, Dong C (2009) Cutting edge: in vitro generated Th17 cells maintain their cytokine expression program in normal but not lymphopenic hosts. J Immunol 182:2565-2568

41. Honkanen J, Nieminen JK, Gao R et al (2010) IL-17 immunity in human type 1 diabetes. J Immunol 185:1959-1967

42. Marwaha AK, Crome SQ, Panagiotopoulos C et al (2010) Cutting edge: increased IL-17-secreting T cells in children with new-onset type 1 diabetes. J Immunol 185:3814-3818 